\title{
Competição de Design da Interação para Mentoria Pós- Disciplina na Graduação: Ideação e Desafios
}

\author{
Yuska Paola Costa Aguiar \\ Departamento de Ciências Exatas (DCX), Universidade Federal da Paraíba (UFPB) \\ Av. Santa Elizabeth, S/N, CEP 58297-000 - Rio Tinto - PB - Brasil \\ yuska@dcx.ufpb.br
}

\begin{abstract}
Resumo. Para favorecer a continuidade dos projetos realizados na disciplina de IHC na graduação, foi idealizada a estratégia de mentoria pós-disciplina, a ser conduzida por professores com atuação complementares. Na inviabilidade de contemplar todos os projetos, uma Competição de Design da Interação foi realizada para seleção das três soluções mais promissoras. Neste artigo relata-se a metodologia aplicada, descreve-se o problema desafio e as soluções propostas, assim como destacam-se as adaptações e as limitações enfrentadas no cenário do ensino remoto. Por fim, são mencionados os direcionamentos pretendidos para a mentoria dos projetos vencedores.
\end{abstract}

\section{A Descontinuidade de Projetos de Design da Interação Pós-Disciplina}

Para alinhar o ensino de Interação Humano-Computador (IHC) às recomendações propostas nos Referenciais de Formação, a abordagem de Aprendizagem Baseada em Projetos (ABP) tem sido relatada para explorar teoria e prática [Boscarioli 2011], [Cerutti 2010], [Sales, Serrano \& Serrano 2020]. Esta abordagem vem sendo adotada para a disciplina de IHC nos cursos de Bacharelado em Sistema de Informação (BSI) e Licenciatura em Ciência da Computação (LCC) da Universidade Federal da Paraíba, Campus IV, desde 2016, sendo aprimorada a cada semestre letivo [Aguiar \& Scherer, 2016].

Neste contexto particular, a execução dos Projetos de Design da Interação cobre o conteúdo Ciclo de Vida do Design da Interação, incluindo técnicas, métodos e geração de artefatos [Rogers, Sharp, \& Preece 2013]. Geralmente, tais projetos são relacionados à solução de um problema real com temas variados cuja execução promove práticas de Design Participativo para consolidação explícita do Design Centrado no Usuário. A prototipagem evolutiva é parte do processo e espera-se um protótipo navegável como resultado. A disciplina é encerrada com a apresentação dos projetos.

Ao longo dos anos, a experiência enquanto docente tem mostrado que promissores Projetos de Design da Interação estão sendo descontinuados - em parte pela inexistência de um projeto integrador entre disciplinas - desconsiderando a viabilidade de evoluir a solução para um produto real. Este cenário desperdiça a possibilidade de explorar os conceitos de inovação, empreendedorismo, gestão de projetos, etc. que são transversais à formação.

Nesta realidade, uma alternativa para impulsionar a continuidade desses projetos seria dar aos alunos um suporte de mentoria pós-disciplina, na tentativa de viabilizar a consolidação de um produto final. Para tanto, se faz necessário o envolvimento de uma equipe de mentores, com expertises complementares, que estejam disponíveis para auxiliar os aprendizes neste processo de formação extraclasse. Para verificar a viabilidade desta proposição, uma etapa inicial consistiu na seleção dos projetos a serem mentorados. Pois, a execução para a totalidade de projetos (média de 8 projetos por semestre) não seria viável 
devido ao esforço, tempo e dedicação demandados. Portanto, surgiu a iniciativa de promover uma Competição de Design da Interação para seleção de projetos a serem continuados.

A inspiração se baseia no modelo da Competição de Design que integra a programação do Simpósio Brasileiro sobre Fatores Humanos em Sistemas Computacionais. A competição tem efeito motivador em seus participantes [Miranda, Viana, Nascimento \& Portela 2019] e estimula a proposição de soluções criativas para problemas práticos, inspirando ideias e oportunidades para novos trabalhos. Diante do exposto, este artigo apresenta o relato da experiência vivenciada no semestre letivo 2019.2, na disciplina de IHC, com a aplicação da Competição de Design da Interação como etapa de seleção de projetos promissores a serem acompanhados por mentores no semestre seguinte (2020.1).

\section{2. "Todo Lixo é um Erro de Design": Competição de Design da Interação}

O Projeto de Design da Interação teve como slogan "Todo lixo é um erro de design", deixando em evidência o tema da Sustentabilidade. O desafio proposto foi de: elaborar uma solução para apoiar a educação e a adoção de práticas sustentáveis no tratamento de lixo. A solução deveria ajudar a lidar com o problema do lixo não tratado de forma sustentável, promovendo a conscientização das pessoas sobre a importância das práticas sustentáveis. A solução proposta deveria explorar diferentes paradigmas de IHC.

Como entrega, além dos artefatos gerados ao longo da execução do projeto (descrição do mínimo produto viável, 3 personas, modelo de navegação, protótipo de baixa-fidelidade e resultado da avaliação com usuário), os alunos foram instruídos a produzir e disponibilizar (i) a solução em nível de protótipo de média/alta-fidelidade; (ii) um vídeo demonstrativo da solução e (iii) um relatório de 3 páginas. Este compilado para a entrega tem por objetivo que os alunos explorem diferentes formas e linguagens para comunicar os resultados de um projeto. As equipes de alunos foram guiadas na realização do projeto de acordo com os o Ciclo de Vida do Design da Interação (Quadro 1).

\section{Quadro 1: Mapeamento entre conteúdos teóricos e atividades práticas}

Identificação de Necessidades e Estabelecimento de Requisitos. Teoria: Técnicas de coleta de dados (Estudo da documentação; Análise comparativa de propostas similares; Aplicação de questionários e entrevistas; Grupo Focal e Observação de Uso); Prática: Adotar 2 ou 3 técnicas de elicitação de requisitos e responder a um conjunto de questões sobre o usuário, seu contexto de uso e atividades a executar na solução proposta.

(re)Design. Teoria: Modelagem conceitual da interface: Personas e Modelo Hierárquico da tarefa; Prática: Aproveitar os dados coletados na atividade anterior e definir 3 personas para representação dos potenciais usuários e definir o Mínimo Produto Viável (MVP)

Construção de uma versão interativa. Teoria: Card sorting, Mapa de navegação e Prototipagem (baixa, média e alta-fidelidade); Prática: Aplicação do card sorting para o MVP e realizar prototipagem de baixafidelidade incluindo mapa de navegação $\left(1^{\circ}\right.$ ciclo) e de média-fidelidade $\left(2^{\circ}\right.$ ciclo)

Validação. Teoria: Avaliação com especialista e com usuários (avaliações rápidas e sujas, percurso cognitivo, heurísticas, inspeção, estudo de campo, grupo focal, verbalização de procedimentos, entrevista/questionário e teste de usabilidade); Prática: Aplicar 2 ou 3 técnicas de avaliação para validação dos protótipos de baixa e média -fidelidade $\left(1^{\circ}\right.$ e $2^{\circ}$ ciclo, respectivamente)

Inicialmente, a estratégia de avaliação seria presencial com a apresentação dos projetos seguida da participação do comitê de avaliação, e divulgação dos três projetos vencedores. No entanto, diante do calendário da Instituição de Ensino Superior (IES), o período 2019.2 foi finalizado com a suspensão das aulas presenciais e o formato remoto foi 
adotado - em consequências da pandemia COVID-19. Conhecendo o perfil socioeconômico dos alunos, a substituição da sala de aula por uma videoconferência (síncrona e online) seria inviável pela impossibilidade de acesso à internet de qualidade, devido ao deslocamento dos alunos para suas residências em áreas isoladas, por exemplo. Esta informação foi confirmada pelos alunos - ao indicarem a dificuldade de acesso à internet fora da universidade - quando consultados sobre a viabilidade de realizar videoconferência (síncrona e online) para as aulas.

Portanto, a avaliação foi assíncrona, via formulário online contendo as seguintes informações para os projetos: nome da solução e objetivo principal; resumo explicativo; link para o protótipo navegável; e, o link para um artigo com detalhes do projeto. $\mathrm{O}$ comitê de avaliação pôde avaliar os projetos no tocante à/ao: (i) adequação da proposta ao tema da Competição de Design; (ii) responsabilidade: preocupação com as questões sociais e legais envolvidas; (iii) rigor: qualidade do trabalho conduzido; (iv) criatividade: potencial da tecnologia proposta para ajudar a resolver o problema em termos de inovação e originalidade; e (v) viabilidade: possibilidade de concretização da proposta (tecnológica e financeira). Adotou-se a escala Likert de 5 níveis (muito alto, alto, médio, baixo e muito baixo). Os avaliadores puderam indicar os projetos que gostariam de mentorar e expor sugestões.

Os integrantes do comitê de avaliação foram os interessados em assumir o papel de mentores ao final da disciplina de IHC, no semestre letivo 2020.1. Envolvê-los desde o início do projeto permite que conheçam as equipes, o percurso percorrido e os resultados alcançados - gerando uma conexão entre eles e os "futuros mentorados". O comitê de avaliação foi composto por 5 avaliadores (aval): aval_1 professor-pesquisador na área de IHC, docente responsável pela disciplina; aval_2 mestrando em Informática com foco em Avaliação de Interface, estagiário docente; e três professores pesquisadores: aval_3 da área de Engenharia de Software, com foco em Gerenciamento de Projetos e Economia Comportamental; aval_4 da área de Empreendedorismo e Inovação Tecnológica; e, aval_5 de Design Sustentável.

Os alunos tiveram contato mais constante com o aval_1 e aval_2, dada a conexão direta destes com a disciplina. Foi prevista a interação dos demais avaliadores com a turma no início do projeto a partir de uma exposição oral (entre 30 e 40 minutos) sobre suas áreas de conhecimento, fazendo o link com a contribuição futura enquanto mentor. Os temas abordados foram: aval_3 Economia Comportamental e Nudges, aval_4 Ciclo de design de Startups e Design Thinking, e aval_5 Princípios da sustentabilidade ño Design.

\section{Projetos da Competição de Design da Interação}

Participaram da competição 7 Projetos de Design da Interação (equipes entre 3 e 5 integrantes), cujas descrições e o $\operatorname{link}^{l}$ dos protótipos dos projetos estão disponíveis a seguir.

Compost visa diminuir o desperdício de frutas e verduras provenientes das feiras, mediando a interação entre doador (feirantes, supermercados, membro da comunidade) e quem realiza a compostagem (agricultores, grupos comunitários). A doação é revertida em hortifrúti cultivados com a compostagem coletiva.

Discard-Map disponibiliza um mapa com indicação de pontos de coleta de acordo com a localização do usuário. Estes consistem em contêineres, separados por tipos de descarte

\footnotetext{
${ }^{1}$ As equipes escolheram a ferramenta de prototipagem adotada e alguns protótipos ficaram indisponíveis após a disciplina ou os links disponíveis podem expirar.
} 
(plástico, papel, metal e vidro). Ao selecionar um contêiner o detalhamento é exibido: localização, tipo de material e nível da capacidade de coleta.

Cabine Sustentável estabelece uma rede de conexão entre consumidores e empresas que geram produtos sustentáveis a partir de material reciclado. As cabines sustentáveis, mapeadas via geolocalização, são pontos de descarte (consumidores) e coleta (empresas). As doações são convertidas em produtos sustentáveis da rede de colaboração. Dicas de ações sustentáveis são apresentadas no aplicativo.

City Helper permite que cidadãos denunciem o descarte indevido do lixo, solicitem instalação de pontos de coleta seletiva ou lixeiras. As denúncias são destinadas às autoridades responsáveis, que buscam, junto à população, combater os problemas reportados. $\mathrm{O}$ aplicativo apoia a gestão participativa e a melhoria da qualidade de vida urbana.

Sustenta Aí tem como foco a separação de material para descarte e reciclagem. Sua dinâmica funciona recompensando quem coleta e quem dispõe material para reciclagem. As experiências de descarte e coleta geram um ranking das ações sustentáveis [Lima et al. 2020].

Reciclaí busca incentivar a reciclagem, com foco em resíduos sólidos, através de um sistema de recompensa por reembolso, oferece prêmios para pontos obtidos na pesagem do material descartado. Ainda, favorece a conexão entre a população e associações e grupos de catadores.

Rota Verde se utiliza da posição do usuário para traçar rotas entre pontos, sugerindo opções com base na emissão de $\mathrm{CO} 2$, preço ou distância, possibilitando aos usuários o benefício da dúvida entre economizar tempo, dinheiro ou ajudar o planeta.

\section{Os vencedores são...}

Para identificação dos projetos vencedores, a média das avaliações feitas pelos 5 avaliadores foi realizada para cada um dos critérios definidos, sendo a escala de avaliação convertida em pontos $(100,90,70,50$ e 30). A média obtida por critério permitiu situar cada projeto em relação aos demais, assim como identificou o projeto mais adequado, criativo, viável, etc. A média total indicou a posição de ranking no pódio dos vencedores (Tabela 1). Os avaliadores demonstraram maior interesse em mentorar os três projetos vencedores: City Helper, Discard-Map e Compost. Os resultados das avaliações foram organizados em uma ficha (Figura 1) para prover uma visão geral relativa aos critérios adotados e pontuação obtida. Os comentários dos avaliadores também foram disponibilizados (anonimamente). Os projetos vencedores foram anunciados no Classroom da turma via slide show. De forma demonstrativa (Quadro 2) alguns comentários feitos para o vencedor: City Helper

Tabela 1. Resultado da avaliação dos projetos

\begin{tabular}{|c|c|c|c|c|c|c|c|}
\hline \multirow[b]{2}{*}{ Projeto } & \multicolumn{5}{|c|}{ Critérios de Avaliação } & \multirow{2}{*}{ Média final } & \multirow{2}{*}{$\begin{array}{c}\text { Posição no } \\
\text { Ranking }\end{array}$} \\
\hline & Adequação & Responsabilidade & Rigor & Criatividade & Viabilidade & & \\
\hline Compost & 100 & 97,5 & 82,5 & 90 & 77,5 & 89,5 & $3^{\circ}$ \\
\hline Discard-Map & 95 & 95 & 95 & 80 & 85 & 90,0 & $2^{0}$ \\
\hline Cabine Sustentável & 95 & 92,5 & 87,5 & 72,5 & 80 & 85,5 & $4^{\circ}$ \\
\hline City Helper & 98 & 94 & 96 & 98 & 94 & 96,0 & $1^{0}$ \\
\hline Sustenta Aí & 96 & 88 & 84 & 78 & 74 & 84,0 & $6^{\circ}$ \\
\hline Reciclaí & 94 & 94 & 82 & 74 & 66 & 82,0 & $7^{\circ}$ \\
\hline Rota Verde & 96 & 90 & 84 & 78 & 78 & 85,2 & $5^{\circ}$ \\
\hline Média & 96.3 & 9.3 .0 & 87.3 & 81.5 & 79.2 & 87.5 & \\
\hline
\end{tabular}




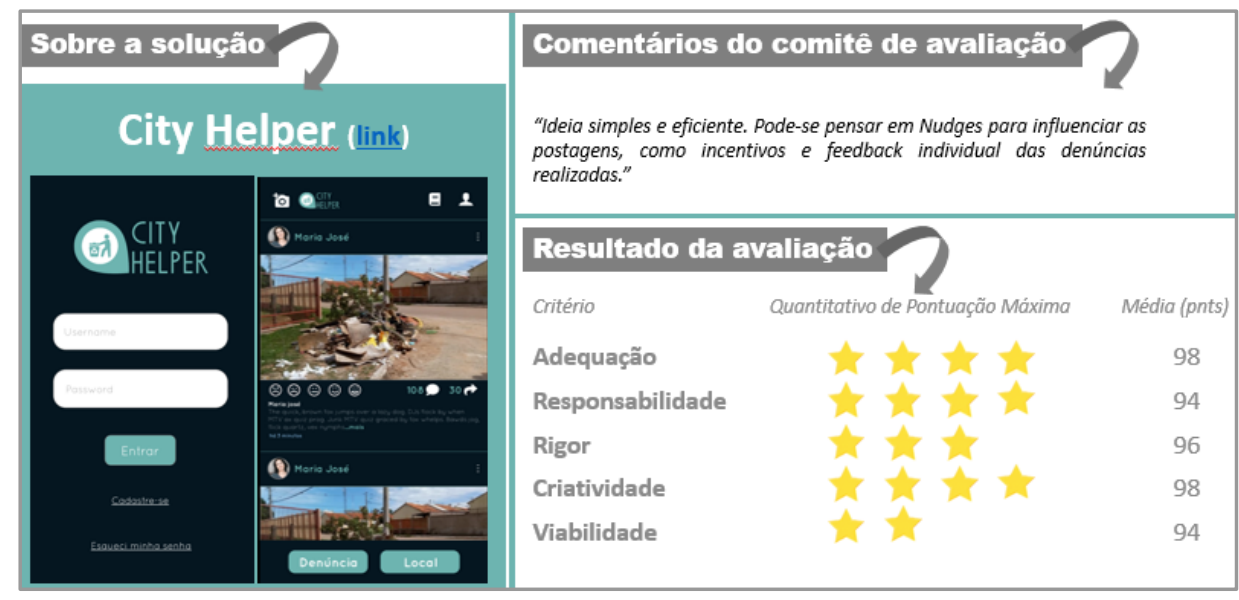

Figura 1. Modelo de ficha do resultado da avaliação para o Projeto City Helper

Quadro 2: Comentários do comitê de Avaliação para o Projeto City Helper

"A ideia pode ser vinculada ou oferecida para órgãos públicos para facilitar os pontos de coleta de lixo,
como também para emissoras de televisão. As emissoras utilizam os aplicativos para saber a opinião
dos telespectadores em seus bairros ou no seu dia-a-dia. [...] oferecer o aplicativo aos candidatos da
próxima eleição [...] para saber o que precisa ser melhorado em cada bairro e focar sua campanha
nisso [...] é preciso analisar se as cores e as fontes são adequadas e legíveis nos ambientes expostos ao
sol."; "Parabéns pela proposta! Vocês atacaram um problema real e propuseram uma solução factivel.
[...] grande valia e utilidade. Deixo com alerta [...] estudar como se dará as denúncias de modo a
preservar a identidade dos denunciantes e como conectar estas denúncias com a prefeitura local. A ideia
é provocar melhorias e não confusões."; e (iii) "Excelente trabalho [...] Em termos de navegação, nada
a acrescentar. Mudaria alguns aspectos [...] para que os registros das notificações fossem mais fáceis
[...] localização de GPS com fotos, numa pegada Instagram. Acho improvável as pessoas entrarem com
tanta informação. A marca e o nome estão sensacionais."

\section{Percepção sobre a Experiência}

Ao final do semestre os alunos puderam indicar a satisfação sobre a disciplina (de forma anônima e opcional) sobre: ter uma competição de design como projeto de disciplina, o tema abordado, a realização do protótipo de média-fidelidade, a participação e feedback dos avaliadores externos, a possibilidade de continuar o projeto em mentoria pós-disciplina, e, o resultado final (Gráfico 1). 20\% dos alunos responderam ao questionário e a percepção destes, embora positiva, não pode ser ampliada para os demais participantes da turma. A limitação inerente de itens objetivos, impossibilita conhecer mais sobre os pontos negativos.

Muito bom Bom Nem bom, nem ruim Ruim Muito ruim

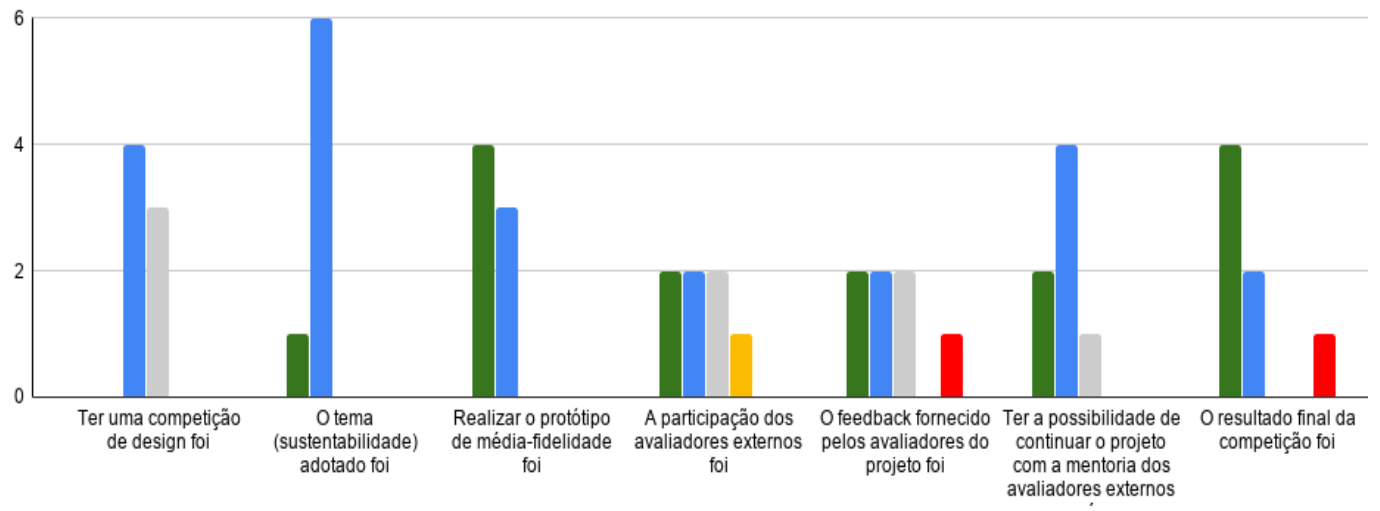

Gráfico 1. Avaliação dos alunos sobre a Competição de Design da Interação 
Apenas dois comentários, em resposta à questão aberta, foram apresentados sobre a competição de design: a) "Perfeito" e b) "Foi bom, só fico imaginando que ter a oportunidade de criar startup pode deixar alguns numa situação chata, pois é possivel que alguns não tenham tempo de trabalhar nessa ideia por conta do final do curso". O segundo comentário faz refletir sobre IHC na estrutura curricular ( $6^{\circ}$ e $8^{\circ}$ período) sendo barreira para a mentoria pós-disciplina.

Vale destacar que a experiência foi realizada em um período atípico, pausado para férias (30 dias), havendo uma ruptura no fluxo contínuo de aprendizado dos alunos. Outra dificuldade foi a interrupção das atividades presenciais nas etapas finais do projeto, levando à consolidação da competição para o formato assíncrono, não proporcionando a troca de experiência mais efetiva entre os alunos e o comitê de avaliação. Ainda, a sobrecarga habitual de final de período, aliada à necessidade de adaptação para o ensino remoto, levou os alunos a solicitarem a supressão da entrega do vídeo demonstrativo das soluções - reduzindo a produção deste artefato. Mesmo assim, a realização dos projetos foi efetiva, não havendo disparidade nos resultados da competição, indicando homogeneidade destes. Ainda, o envolvimento dos avaliadores externos diversificou os olhares sobre os projetos, enriquecendo os comentários e sugestões dirigidos às equipes. A adoção da abordagem metodológica híbrida de aprendizagem ativa (gamificação e ABP) favoreceu o engajamento.

Diante do contexto da pandemia, a IES suspendeu o período 2020.1 e ofertou um período suplementar não obrigatório para professores e alunos, impedindo a executar o as atividades de mentoria pós-disciplina. Eram previstas reuniões quinzenais dos projetos vencedores com os mentores, durante o período de um semestre letivo, para implementação do Value Proposition Design [Osterwalder et al. 2014] a partir das etapas de: Canvas, Design, Teste e Desenvolvimento. O objetivo pretendido consistia em refinar as soluções propostas para consolidá-las e disponibilizá-las enquanto produto final.

\section{Referências}

Aguiar, Y. P. C, Scherer, D. (2016) Da teoria à prática: uma abordagem de ensino de IHC baseado em papéis. In Workshop sobre Ensino de IHC (WEIHC). ACM.

Boscarioli, C. (2011). O Ensino de IHC por Meio de Aprendizagem Baseada em Problemas: Um Relato de Experiência. In Workshop sobre Ensino de IHC (WEIHC). CEUR-WS.

Cerutti, D. M. L. (2010). Ensino de IHC: Desconstruindo interfaces em sala de aula. In Workshop sobre Ensino de IHC (WEIHC). ACM.

Lima, D. H. E. D. O., Oliveira, J. V. dos S., da Silva, M. N. P., \& Aguiar, Y. P. C. (2020). Teoria e Prática de IHC na Concepção do Sustenta Aí: Um Aplicativo para Promoção de Ações Sustentáveis. In Congresso sobre Tecnologias na Educação (Ctrl-e). SBC.

Miranda, P., Viana, J., Nascimento, E., \& Portela, C. (2019). O Uso de Estratégias de Gamificação em uma Disciplina de IHC: Um Relato de Experiência. In Anais Estendidos do XVIII Simpósio Brasileiro sobre Fatores Humanos em Sistemas Computacionais. SBC.

Osterwalder, A., Pigneur, Y., Bernarda, G., \& Smith, A. (2014). Value proposition design: How to create products and services customers want. John Wiley \& Sons.

Rogers, Y., Sharp, H., \& Preece, J. (2013). Design de Interação. Bookman Editora.

Sales, A. B. D., Serrano, M., \& Serrano, M. (2020). Aprendizagem Baseada em Projetos na Disciplina de Interação Humano-Computador. Revista Ibérica de Sistemas e Tecnologias de Informação, (37), 49-64. 